\title{
A PRÁTICA DE JOGOS COMPUTADORIZADOS EM UM GRUPO DE ADOLESCENTES ${ }^{1}$
}

\author{
COMPUTER GAME PRACTICE IN \\ AN ADOLESCENTS' GROUP
}

\author{
Miriam Schifferli HOFF ${ }^{1}$ \\ Solange Muglia WECHSLER ${ }^{2}$
}

\begin{abstract}
RESUMO
Por meio de um questionário elaborado pela autora principal e aplicado coletivamente, investigou-se a prática de jogos de computador em um grupo de adolescentes (40 meninos e 26 meninas, de $6^{a}$ - $8^{a}$ séries, de uma escola particular de Campinas/SP; nível socioeconômico médio/ médio-alto). Meninos jogavam mais do que meninas, mas, nos dois sexos, o tempo investido decresceu com a maior instrução. Entre os meninos destacaram-se: tempo de jogo sob controle heterônomo (pais) ou autônomo; preferência dos mais novos por jogo de esporte ou ação e dos mais velhos, por esporte; os determinantes principais da preferência foram desafios/exigências de estratégias e conteúdo do jogo. Para as meninas predominaram o controle autônomo do tempo de jogo e seu grau de motivação; não se revelaram preferências claras por diferentes tipos de jogos, mas desafios/exigências de estratégias e diversão/ interesse despertados foram as principais razões de preferências individuais. As discussões focaram as diferenças de gênero e controle pelos pais.
\end{abstract}

Palavras-chave: jogos computadorizados; adolescentes; hábitos e preferências; gênero.

(1) Profa. Dra. da Graduação no Curso de Psicologia da PUC-Campinas. Sub-projeto da tese de doutorado da primeira autora (2001), financiado pela PUC-Campinas. As autoras agradecem à Direção, ao Serviço de Orientação Educacional, aos professores e aos alunos da instituição escolar campineira que acolheu a pesquisa.

Docente da Faculdade de Psicologia, PUC-Campinas, e-mail: mhoff@uol.com.br

End. (correspondência com Editor): R. Coelho Neto, 222, ap. 44, Guanabara, Campinas-SP - Fone: 3232-2326 CEP 13023-020 - E-mail: mhoff@uol.com.br.

(2) Profa. Dra. do curso de Pós-Graduação em Psicologia, Faculdade de Psicologia da PUC-Campinas. Orientadora; Doutorado em Psicologia, PUC-Campinas; e-mail: wechsler@lexxa.com.br. Docente da Faculdade de Psicologia, PUC-Campinas. 


\begin{abstract}
With a questionnaire elaborated by the main author and collectively administered, it was examined the computer game-playing habits among an adolescents' group (40 males and 26 females, $6^{\text {th }}$ to $8^{\text {th }}$ grade, from a private school of Campinas/SP and with middle/middle-high socioeconomic status). Males played more than females but in both sexes, the time dedication decreased from $6^{\text {th }}-7^{\text {th }}$ to $8^{\text {th }}$ grade. Among males became evident: the heteronomous control (parents) of time playing and the autonomous control; a predominant preference to sport games among the elders, and to sport or action games among the youngsters; the main causes of predilection were the challenges/strategies demands and the game contents. Among females, predominated the autonomous control and their motivation degree to computer games; there haven't clearly manifested preferences to different game types, but the challenges/ strategies demands and the aroused amusement/interest were the major reasons for individuals predilections. Discussions focused the identified gender differences and parent's control.
\end{abstract}

Key-words: computer games; adolescents; habits and preferences; gender differences.

No Brasil, a difusão dos computadores pessoais deu-se nos anos 90 (Godoy, 1996). Ao final de 2000 , eram 11 milhões os computadores instalados e 10 milhões de usuários conectados à internet, dos quais quase um milhão eram adolescentes (Nogueira, Vargas e Nathan, 2000). Apesar de parcela pequena da população, trata-se de grande número de crianças e adolescentes apropriando-se das novas tecnologias, muitos possivelmente tendo os jogos computadorizados como porta de entrada (Greenfield, 1984/19882 ; Retschitzki \& Gurtner, 1995; Sangiorgi,1988).

Em países de língua inglesa, pré-escolares já usam o computador, mais com jogos cujo tempo cresce ao longo desta faixa etária, enquanto decai aquele com TV (Downes, Reddacliff \& Moont, 1995; Huston, Wright, Marquis \& Green, 1999). A maioria dos alunos de $4^{\mathrm{a}}$ a $8^{\mathrm{a}}$ série praticajogos computadorizados em casa; mais de $60 \%$ consideram jogar além do pretendido, mas só em poucos foram localizados indícios de conduta "aditiva" (Phillips, Rolls, Rouse \& Griffiths, 1995). Da $4^{a}$ à $8^{a}$ série, o jogo domiciliar declina, mas aumenta em fliperamas; decai o tempo com jogos eletrônicos e o interesse por jogos educativos, enquanto cresce pelos de lazer, com preferência por jogos violentos nas diferentes séries e nos dois sexos (Buchman \& Funk 1996). Assim, em países de língua inglesa, o padrão geral é de movimento para o jogo fora de casa, interesse por jogos violentos e menor tempo com o crescer da idade.

Meninos jogam mais e freqüentam mais os fliperamas do que meninas (Barnett, Vitaglione, Harper, Quackenbush, Steadman \& Valdez, 1997; Buchman \& Funk, 1996; Cesarone, 1998; Satoshi, Yamada, Masuda \& Tada, 1993; Van Schie \& Wiegman, 1997). Tais diferenças refletem estereótipos de gênero e, para os próprios sujeitos, a aprovação dos pares depende do tipo de prática (Funk \& Buchman, 1996a). Maior tempo com jogos de computador associou-se à baixa auto-estima

(2) Nas referências, a primeira data corresponde à edição original e a segunda, à edição consultada em português. 
em meninas de $7^{\mathrm{a}}$ e $8^{\mathrm{a}}$ séries, que se percebiam aprovadas pelos pares quando sua prática era moderada e, em meninos de $6^{a}$ série, forte preferência por jogos violentos associou-se a autopercepções mais negativas (Funk \& Buchman, 1996b). Mas, em uma amostra japonesa (dois sexos, $4^{\mathrm{a}}$ - $6^{\mathrm{a}}$ séries), a freqüência do jogar não se correlacionou popularidade dos sujeitos (Sakamoto, 1994), o que aponta a conveniência de mais estudos interculturais sobre as variáveis sexo e aceitação pelos pares. Outro estudo japonês constatou mais prática de videogames entre crianças obesas (Satoshi, Yamada, Masuda \& Tada, 1993), dando outra indicação de possíveis relações entre o grau de dedicação a jogos e variáveis sócio-afetivas. Entre adolescentes, outras diferenças sexuais referem-se aos motivadores do jogar, às preferências por jogos e à avaliação de seus atributos (Barnett, Vitaglione, Harper, Quackenbush, Steadman \& Valdez, 1997) e, em universitários, o sexo masculino tem mostrado melhor desempenho (Brown, Hall, Holtzer, Brown \& Brown, 1997).

Para crianças e adolescentes, jogar é absorvente e inofensivo, exceto se consumir muito tempo, e jogam pela diversão, desafio e pelo fato de amigos jogarem (Griffiths, 1997), e também pelo afastamento de problemas reais e envolvimento na ação (Selnow, 1984). Jogadores interessados e muito frequentes não diferem, em personalidade ou sociabilidade, daqueles pouco frequentes/ pouco interessados, mas relatam mais que jogar dá um senso de importância e tendem a assumir mais riscos em situações de jogo (Barnett, Vitaglione, Harper, Quackenbush, Steadman \& Valdez, 1997, Glissov et al. ${ }^{3}$, 1994; Gupta, 1994, Gupta \& Derevensky, 1996). Quem joga muito vê os jogos como companhia mais fácil de interagir, que dá mais satisfação do que os próprios amigos (Selnow, 1984). A prática de jogos de computador não tem prejudicado o rendimento escolar de crianças (Emes, 1997) ou universitários (McCutcheon \& Campbell, 1986), com relatos de malefícios só em uma minoria de crianças, com jogo de 3 ou mais horas semanais (Biegen, 1985).

Na literatura brasileira dos anos 90 , só foi localizado um estudo do perfil de dois grupos de jogadores de videogames, usuários (só do sexo masculino) de duas locadoras de cartuchos (Campos, Yukumitsu, Fontealba e Bomtempo, 1994): 22 adolescentes (12-17 anos; $6^{\mathrm{a}}$ série $/ 1^{\circ} \mathrm{Grau}$ a $3^{\mathrm{a}}$ série $/ 2^{\circ} \mathrm{Grau}$ ) e 14 meninos (6-11 anos; pré-primário a $6^{\mathrm{a}}$ série). Os adolescentes jogavam, por dia, o dobro do tempo dos meninos (3h10 vs $1 \mathrm{~h} 50$ ), o que se opõe a dados internacionais de queda na dedicação com o avanço etário. Nos dois grupos, Pit Fighter, o jogo preferido, foi julgado pouco agressivo ou algo agressivo, em oposição a dois juízes psicólogos que o qualificaram como jogo de luta, muito violento e competitivo. Pouca/nenhuma agressividade e pouca ação filiaram-se à rejeição de um jogo e alguma agressividade e ação contínua, a uma maior preferência, o que é consistente com dados americanos (Buchman \& Funk, 1996; Selnow, 1984).

Diante dos muitos estudos internacionais sobre padrões de jogo de adolescentes e crianças, sobressai a ausência de dados nacionais. O desconhecimento relativo a jogadores de videogames (Campos, Yukumitsu, Fontealba e Bomtempo, 1994) estende-se aos jogos de computador. Ainda que a caracterização desta prática não informe sobre aprendizagens subjacentes a diferentes jogos e suas influências psicológicas, pode oferecer um ponto de partida para pesquisas destes aspectos. Com esta ótica, objetivou-se investigar os hábitos de um grupo de adolescentes dos dois sexos na sua prática domiciliar de jogos de computador e identificar

\footnotetext{
(3) A menção parcial aos autores, no texto e nas referências, reproduz o informe disponibilizado na base de dados online consultada.
} 
diferenças de gênero. Outro propósito foi buscar parâmetros para outra pesquisa: selecionar um dos jogos preferidos nesse grupo, como alvo de uma pesquisa microgenética dos processos cognitivos e resolutivos de jogadores novatos ao longo do seu gradativo domínio do jogo. Como uma aproximação inicial à área de jogos de computador, configurou-se, então, um estudo exploratório e descritivo, centrado na análise quantitativa de informes, opiniões e percepções dos próprios jogadores.

\section{MÉTODO}

Sujeitos. Participaram 92 sujeitos (53 meninos e 39 meninas), de três classes mistas $\left(6^{\mathrm{a}}, 7^{\mathrm{a}}\right.$ e $8^{\mathrm{a}}$ séries de $\left.1^{\circ} \mathrm{Grau}\right)$ de uma escola particular de Campinas/SP que atende uma clientela de nível socioeconômico médio/médioalto, com ensino do pré-escolar ao $2^{\circ} \mathrm{Grau}$. Destas três classes, designadas pelo Serviço de Orientação Educacional em função de disponibilidades ligadas às atividades acadêmicas, foi extraída a amostra estudada. Esta ficou integrada por 66 sujeitos ( 40 meninos e 26 meninas), selecionados em função da posse de computador em casa, a partir de um questionário aplicado ao conjunto de 92 alunos das três classes.

Os 40 meninos dividiram-se, respectivamente, em 14,12 e 14 de $6^{a}, 7^{a}$ e $8^{a}$ séries; as 26 meninas, em 12, 2 e 12. Como só duas meninas de $7^{a}$ série tinham computador, para balancear a amostra, aglutinaram-se as $6^{\mathrm{a}}$ e $7^{\mathrm{a}}$ séries. Assim, quanto à instrução e idade, a amostra final comportou dois grupos: Grupo I (6 $6^{\mathrm{a}}$-7 $^{\mathrm{a}}$ séries: 26 meninos e 14 meninas; idades médias de 12,9 e 12,8 anos) e Grupo II ( $8^{\mathrm{a}}$ série: 14 meninos e 12 meninas; idades médias de 14,5 e 14,6 anos).

Instrumento. Um questionário elaborado pela autora principal, com 10 questões, abertas e fechadas, sobre: a) existência, ou não, de computador em casa e uso pelo sujeito; b) a prática de jogos de computador pelo sujeito, sua freqüência e razões desta freqüência; c) tempo gasto e número de jogos em cada situação de jogo; d) indicação de quatro jogos que sabia jogar; g) nome e tipo do jogo preferido, os requisitos para êxito neste jogo e razões da preferência.

Procedimento. O questionário foi coletivamente aplicado em cada classe, pela pesquisadora (1997). Os informes aos alunos incluíram: a) o caráter opcional e cooperativo da participação; b) a importância de respostas individuais e opiniões sinceras; d) o sigilo sobre a identidade de cada um, nenhum aluno indicando seu nome. As questões foram lidas, uma a uma, tendo-se dado tempo para responderem. Em cada classe, a aplicação demandou uma hora-aula (50 minutos), no máximo, e teve o consentimento e participação de todos os alunos presentes.

\section{RESULTADOSE DISCUSSÃO}

Entre os 66 sujeitos, o tempo de posse do computador ( 3 meses a 17 anos) concentrou-se entre 1-5 anos. À época da coleta, meninos e meninas mais velhos/maior instrução tinham computador há mais tempo do que os de menor instrução/mais novos (mediana: 2,75 anos vs. 1,75 ano). Nos dois grupos, 90,0 a 100,0\% dos meninos e meninas usavam mais o computador com jogos e, depois, com atividades escolares. Cerca de $40,0 \%$ dos meninos dos dois grupos e 30,0\% e $40,0 \%$ das meninas, nos Grupos I e II, usavam a internet. Outros usos foram praticamente nulos. O emprego maior com jogos reforçou os indicativos de que constituem a porta de acesso ao computador para muitos adolescentes e crianças (Greenfield, 1984/1988; Retschitzki \& Gurtner, 1995; Sangiorgi, 1988). Quando da coleta (1997), menos da metade dos sujeitos usava a internet. Sua ampla difusão e o uso atual de e-mail e chats por adolescentes (Nogueira, Vargas e 
Nathan, 2000) poderiam sugerir desatualização dos dados do estudo e improcedência de sua publicação agora. Mas, exatamente pela rapidez das mudanças na informática e a ausência de estudos nacionais, apesar da especificidade da amostra, os dados oferecem uma referência para aquilatar a expansão de interações virtuais entre crianças e adolescentes.

Os sujeitos informaram se jogavam todo dia, semanalmente (quantos dias), às vezes (quantas, num mês) ou nunca, e o tempo habitual em cada ocasião. Cada situação durou de 0,5 a 7,0h de jogo. Para sujeitos que indicaram o número de vezes por mês, foi calculada sua média semanal. Assim, a freqüência de jogo resumiu-se em diária ou semanal (um ou alguns dias por semana). Para maior síntese, obteve-se o tempo semanal de jogo de cada sujeito (freqüência $x$ duração em cada vez), que variou de $0,5 \mathrm{~h}$ a $49,0 \mathrm{~h}$, com concentração entre $0,5 \mathrm{~h}$ - 9,5h para os 40 meninos e $0,5 \mathrm{~h}-3,5 \mathrm{~h}$, para as meninas (Tabela
1). Meninos jogavam mais do que meninas na amostra total $(6,2 \mathrm{~h}$ vs. $1,3 \mathrm{~h})$ e em cada grupo (I: 7,0h vs. $2,4 \mathrm{~h}$; II: 5,0h vs. 1,1h), coincidindo com evidências internacionais (Barnett, Vitaglione, Harper, Quackenbush, Steadman \& Valdez, 1997; Buchman \& Funk, 1996; Cesarone, 1998; Satoshi, Yamada, Masuda \& Tada, 1993; Van Schie \& Wiegman, 1997). Os dados apontaram, ainda, mais jogo entre meninos mais novos (I: 7,0h; II: 5,0h) e meninas mais novas (I: 2,4h; II: 1,1h). Embora opostos aos dados de Campos, Yukumitsu, Fontealba e Bomtempo (1994), concordaram com achados americanos sobre menor dedicação a jogos de computador com o avanço da escolaridade (Buchman \& Funk, 1996).

As 25 meninas jogavam pouco (mediana: $1,3 \mathrm{~h}$ semanais). Diante de dados americanos $-65,0 \%$ de meninos de $7^{a}-8^{a}$ séries com 1 a 6 horas de jogo semanal (Funk, apud Cesarone, 1994) - o tempo semanal desses meninos brasileiros não se configura excessivo, pois, no conjunto deles, metade jogava até

Tabela 1. Distribuição do tempo semanal investido em jogos computadorizados.

\begin{tabular}{|c|c|c|c|c|c|c|}
\hline Sexo & \multicolumn{6}{|c|}{ Masculino } \\
\hline \multirow{2}{*}{$\begin{array}{l}\text { Tempo } \\
\text { Semanal } \\
\text { de Jogo } \\
\text { (horas) }\end{array}$} & \multicolumn{2}{|c|}{$\begin{array}{l}\text { Grupo I } \\
(N=26)\end{array}$} & \multicolumn{2}{|c|}{$\begin{array}{l}\text { Grupo II } \\
(N=14)\end{array}$} & \multicolumn{2}{|c|}{$\begin{array}{l}\text { Amostra Total } \\
(\mathrm{N}=40)\end{array}$} \\
\hline & $f$ & $\%$ & $f$ & $\%$ & $f$ & $\%$ \\
\hline $0,5-3,4$ & 8 & 30,8 & 6 & 42,9 & 14 & 35,0 \\
\hline $3,5-6,4$ & 4 & 15,4 & 3 & 21,4 & 7 & 17,5 \\
\hline $6,5-9,4$ & 7 & 26,9 & 3 & 21,4 & 10 & 25,0 \\
\hline $9,5-12,4$ & 1 & 3,8 & - & - & 1 & 2,5 \\
\hline $12,5-15,4$ & 2 & 7,7 & 1 & 7,1 & 3 & 7,5 \\
\hline$\geq 15,5$ & $4^{* *}$ & 15,4 & $1^{* \star *}$ & 7,1 & $5^{\star \star \star \star *}$ & 12,5 \\
\hline Total & 26 & 100,0 & 14 & 100,0 & 40 & 100,0 \\
\hline $\begin{array}{c}\text { Tempo } \\
\text { mediano de } \\
\text { Jogo } \\
\text { Semanal }\end{array}$ & \multicolumn{2}{|c|}{7,0} & \multicolumn{2}{|c|}{5,0} & \multicolumn{2}{|c|}{6,2} \\
\hline
\end{tabular}

\begin{tabular}{|c|c|c|c|c|c|c|}
\hline Sexo & \multicolumn{6}{|c|}{ Feminino } \\
\hline \multirow{2}{*}{$\begin{array}{l}\text { Tempo } \\
\text { Semanal } \\
\text { de Jogo } \\
\text { (horas) }\end{array}$} & \multicolumn{2}{|c|}{$\begin{array}{l}\text { Grupo I } \\
\left(N=13^{*}\right)\end{array}$} & \multicolumn{2}{|c|}{$\begin{array}{l}\text { Grupo II } \\
(\mathrm{N}=12)\end{array}$} & \multicolumn{2}{|c|}{$\begin{array}{c}\text { Amostra Total } \\
\left(\mathrm{N}=25^{\star}\right)\end{array}$} \\
\hline & $f$ & $\%$ & $f$ & $\%$ & $f$ & $\%$ \\
\hline $0,5-1,4$ & 4 & 30,7 & 10 & 83,4 & 14 & 56,0 \\
\hline $1,5-2,4$ & 3 & 23,1 & - & - & 3 & 12,0 \\
\hline $2,5-3,4$ & 2 & 15,4 & 1 & 8,3 & 3 & 12,0 \\
\hline $3,5-4,4$ & 1 & 7,7 & - & - & 1 & 4,0 \\
\hline$\geq 4,5$ & $3^{* *}$ & 23,1 & $1^{\star \star \star}$ & 8,3 & $4^{\star \star \star \star}$ & 16,0 \\
\hline Total & 13 & 100,0 & 12 & 100,0 & 25 & 100,0 \\
\hline $\begin{array}{c}\text { Tempo } \\
\text { mediano } \\
\text { de Jogo } \\
\text { Semanal }\end{array}$ & \multicolumn{2}{|c|}{2,4} & \multicolumn{2}{|c|}{1,1} & \multicolumn{2}{|c|}{1,3} \\
\hline
\end{tabular}

Grupo I: $6^{\mathrm{a}}$ e $7^{\mathrm{a}}$ séries Grupo II: $8^{\mathrm{a}}$ série $\quad \mathrm{N}$ : total de sujeitos

*: excluída uma menina que não usava computador Tempo semanal de jogo $\geq 15,5 \mathrm{~h}$, no sexo masculino - **: 21,$0 ; 28,0 ; 35,0$ e 49,0h ***:21,0h ****:21,0;21,0;28,0; 35,0 e $49,0 h$

Tempo semanal de jogo $\geq 4,5 \mathrm{~h}$, no sexo feminino - **: 17,$5 ; 21,0 \mathrm{~h} \quad * * *: 28,0 \mathrm{~h} \quad * * * *: 17,5 ; 21,0 \mathrm{~h}$ e $28,0 \mathrm{~h}$ 
perto de 1,0 hora diária e a outra metade, por mais tempo. Tais valores são inferiores ao tempo dedicado à TV por adultos brasileiros que é de 3,0 horas diárias, em média, enquanto crianças assistem por 4,0 horas ou mais (Azambuja, 1995; Mendes, 1995). Ainda que a maioria não jogasse excessivamente, sobressaem casos como o dos 5 meninos (21,0h a 49,0 h semanais de jogo) e de 3 meninas (17,5h a $28,0 \mathrm{~h})$, cujo tempo informado representava cerca de 4,5 e 3,0 horas diárias de jogo, respectivamente. Tais casos ganham importância diante dos indicadores na literatura internacional sobre possíveis associações entre dedicação excessiva a jogos e variáveis sócio-afetivas (ex., baixa auto-estima, dificuldades nas relações interpessoais).

Ainda, cabem mais estudos para identificar se o tempo de jogo, de fato, cresce, com a maior escolaridade (Campos, Yukumitsu, Fontealba e Bomtempo, 1994) ou se decresce, como verificado aqui e externamente (Buchman \& Funk, 1996). Uma queda é consistente com uma diversificação de interesses e compromissos com o avanço da adolescência. Também, com a possibilidade de menor interesse em função de maior familiaridade e a perda do caráter de novidade. Apóia esta consideração o fato de que, na amostra brasileira estudada, os meninos mais velhos possuíam computador há mais tempo e jogavam menos do que os mais novos. Mesmo assim, em vista das discrepâncias entre estudos, a questão pede mais exame.

Sobre a freqüência do jogar emergiram quatro categorias de razões (Tabela 2): a) não gosta muito ou enjoou (baixa motivação); b) gosta muito, os pais não controlam, mas divide seu tempo entre suas ocupações (motivação alta sob controle autônomo); c) gosta muito e os pais permitem que jogue o quanto desejar (motivação alta; dedicação livre); d) jogaria mais, apesar de suas ocupações, mas os pais só permitem certo tempo (motivação alta sob controle heterônomo).

Com diferença significativa $\left(\chi^{2}=12,94\right.$; $\left.\chi^{2} \mathrm{c}=9,21 ; \mathrm{g} . \mathrm{I}=2 ; \mathrm{p}<0,01\right)$, na amostra total masculina, predominaram o controle autônomo (50,0\%) e o heterônomo (35,0\%); na feminina, o controle autônomo $(60,0 \%)$ e sua motivação pelos jogos (alta ou baixa: $40,0 \%)$. Mas, entre os 40 meninos, o tempo mediano de jogo semanal $(6,5 \mathrm{~h}$ e $7,0 \mathrm{~h})$ foi 0 mesmo, para as duas formas de controle. A sugestão de mesma influência do autocontrole e controle parental não se sustenta nos grupos instrucionais/etários: entre os mais novos, sob controle heterônomo, o tempo mediano de jogo, no mínimo, tendeu a ser inferior (5,3 h) ao daqueles sob controle autônomo (7,0 h); entre os mais velhos deu-se o inverso (controle dos pais: $7,0 \mathrm{~h}$; autônomo: $4,5 \mathrm{~h}$ ). Uma hipótese seria a de melhor controle parental junto aos filhos menores (Campos, Yukumitsu, Fontealba e Bomtempo, 1994) e melhor autocontrole entre adolescentes mais velhos. Nos dois sexos, inconsistências, possivelmente devidas aos tamanhos pequenos dos extratos, restringem os dados, mesmo nas amostras totais: a) meninos que jogavam livremente (4 dos 40) com menos jogo $(2,9 \mathrm{~h})$ do que daqueles sob o controle dos pais $(7,0 h)$ ou autocontrole $(6,5 h) ; b)$ dedicação maior das meninas que jogavam livremente $(4,5 \mathrm{~h})$ do que de meninos em igual condição $(2,9 \mathrm{~h})$, opondo-se às evidências na literatura; c) mesma dedicação entre meninas pouco motivadas $(0,9 \mathrm{~h})$ e aquelas motivadas, mas sob autocontrole $(1,1 \mathrm{~h})$ o que é pouco razoável. Cabe verificar com amostras maiores, o grau em que crianças e adolescentes jogam, ou não, livremente e suas repercussões. Também, se pais buscam conhecer o conteúdo dos jogos praticados por seus filhos, não para mero controle, mas para estimular nos filhos uma atitude reflexiva e crítica sobre este tipo de lazer. 


\begin{tabular}{|c|c|c|c|c|c|c|}
\hline \multirow{6}{*}{ 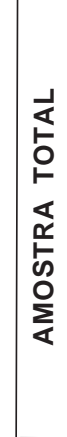 } & $\sum_{i}^{\bar{\sigma}}$ & $\begin{array}{l}0 \\
0 \\
0\end{array}$ & $\stackrel{-1}{-1}$ & $\stackrel{L}{\sim}$ & ' & $\stackrel{m}{\rightarrow}$ \\
\hline & II & $\begin{array}{l}O \\
\text { İ }\end{array}$ & $\begin{array}{l}0 \\
0 \\
0\end{array}$ & $\begin{array}{l}0 \\
0 \\
0 \\
-1\end{array}$ & ' & : \\
\hline & 4 & 0 & $\stackrel{\sim}{\sim}$ & 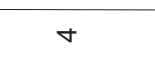 & , & $\stackrel{\sim}{\sim}$ \\
\hline & $\sum_{1}^{\delta}$ & $\stackrel{\llcorner}{\sim}$ & $\begin{array}{l}L_{0} \\
0\end{array}$ & $\stackrel{a}{i}$ & $\stackrel{\circ}{i}$ & $\stackrel{N}{0}$ \\
\hline & $\begin{array}{l}\text { II } \\
z\end{array}$ & $\begin{array}{l}0 \\
\text { Dे }^{\circ}\end{array}$ & $\begin{array}{l}0 \\
\text { in }\end{array}$ & $\begin{array}{l}0 \\
0 \\
0\end{array}$ & $\begin{array}{l}\text { ० } \\
\text { in }\end{array}$ & $\begin{array}{l}0 \\
\stackrel{-}{0}\end{array}$ \\
\hline & + & $\sim$ & 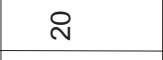 & $\nabla$ & $\underset{ন}{\triangleleft}$ & o \\
\hline \multirow{6}{*}{$\begin{array}{l}\overline{\overline{0}} \\
\frac{0}{2} \\
\frac{0}{0} \\
0\end{array}$} & $\sum_{1}^{D}$ & $\begin{array}{l}\infty \\
0^{\infty}\end{array}$ & $\begin{array}{l}0 \\
0 \\
0\end{array}$ & $\stackrel{\circ}{\text { m }}$ & ' & 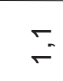 \\
\hline & II & $\begin{array}{l}0 \\
\text { L্ }\end{array}$ & $\begin{array}{l}0 \\
0^{\circ}\end{array}$ & Oㅁ & ' & : \\
\hline & 4 & $m$ & 0 & $m$ & ' & 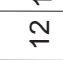 \\
\hline & $\sum_{1}^{\delta}$ & $\stackrel{\sim}{\sim}$ & $\stackrel{\llcorner}{\sigma}$ & $\vec{\sim}$ & $\stackrel{\circ}{N^{\prime}}$ & $\stackrel{\circ}{\circ}$ \\
\hline & II & $\begin{array}{l}m \\
\stackrel{\sim}{\sim}\end{array}$ & $\begin{array}{l}\stackrel{\leftrightarrow}{ } \\
\stackrel{y}{y}\end{array}$ & $\begin{array}{l}m \\
\underset{f}{f}\end{array}$ & $\begin{array}{l}\stackrel{L}{\infty} \\
\stackrel{\infty}{N}\end{array}$ & $\begin{array}{l}0 \\
8 \\
8\end{array}$ \\
\hline & $\leftarrow$ & $\sim$ & 0 & $N$ & $\nabla$ & ন \\
\hline \multirow{6}{*}{ 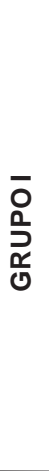 } & $\sum_{1}^{D}$ & م & $\begin{array}{l}\circ \\
\text { m }\end{array}$ & $0_{0}^{\circ}$ & ' & $\stackrel{\nabla}{\sim}$ \\
\hline & $\sum_{u}^{\prime \prime}$ & $\overrightarrow{\text { d }}$ & In & $\hat{\imath}$ & ' & $\begin{array}{l}0 \\
0 \\
0 \\
0\end{array}$ \\
\hline & 4 & $m$ & $\sigma$ & $r$ & ' & $\stackrel{m}{-1}$ \\
\hline & $\sum_{1}^{D}$ & & $\stackrel{\circ}{i}$ & $\begin{array}{l}\text { क् } \\
\stackrel{D^{-}}{ }\end{array}$ & $\begin{array}{l}m \\
\text { in }\end{array}$ & $\stackrel{\circ}{i}$ \\
\hline & $\begin{array}{l}\text { II } \\
\Sigma \\
\Sigma\end{array}$ & ' & $\begin{array}{l}\infty \\
\aleph_{n}^{\infty}\end{array}$ & $\hat{\kappa}$ & $\begin{array}{l}L^{n} \\
\infty^{\circ}\end{array}$ & $\begin{array}{l}0 \\
0 \\
0 \\
0\end{array}$ \\
\hline & $\leftarrow$ & ' & $\underset{\sim}{J}$ & $N$ & 우 & $\stackrel{\sim}{\sim}$ \\
\hline 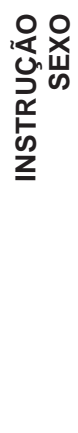 & 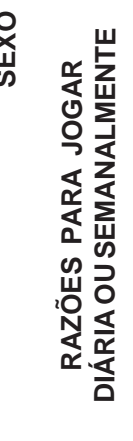 & 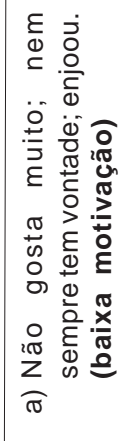 & 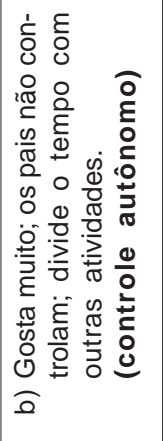 & 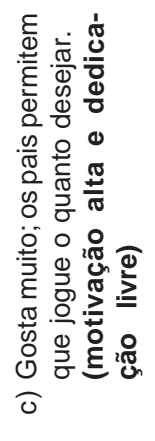 & 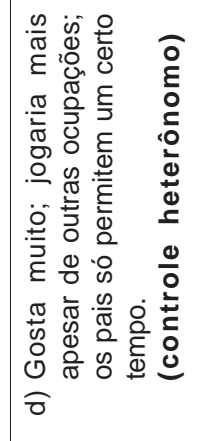 & 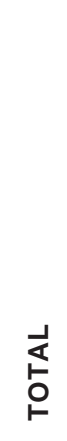 \\
\hline
\end{tabular}




\begin{tabular}{|c|c|c|c|c|c|c|c|c|c|c|c|c|c|}
\hline \multirow{4}{*}{ 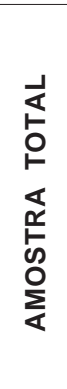 } & \multirow{2}{*}{$\begin{array}{l}\widetilde{I} \\
\mathbb{N} \\
\text { II } \\
z \\
u\end{array}$} & $\circ$ & $\begin{array}{l}\circ \\
\text { i }\end{array}$ & $\begin{array}{l}0 \\
\text { in }\end{array}$ & $\begin{array}{l}0 \\
\text { in }\end{array}$ & I & \begin{tabular}{l}
0 \\
$\stackrel{-}{\circ}$ \\
\hdashline
\end{tabular} & $\circ$ & $\stackrel{\infty}{\stackrel{\infty}{\Gamma}}$ & $\begin{array}{l}\stackrel{0}{\mathbb{T}} \\
\underset{\sim}{7}\end{array}$ & $\stackrel{\sim}{\sigma}$ & $\stackrel{\llcorner}{\stackrel{\sim}{\sim}}$ & 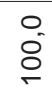 \\
\hline & & 4 & $\sim$ & $m$ & م & ' & 욱 & 4 & ᄀ & $m$ & $\rightarrow$ & $m$ & $\stackrel{\sim}{N}$ \\
\hline & $\begin{array}{l}\widehat{o} \\
\text { II }\end{array}$ & $\therefore$ & $\overrightarrow{N^{2}}$ & 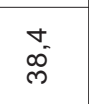 & $\begin{array}{l}\infty \\
\stackrel{\infty}{-} \\
\text { - }\end{array}$ & $\hat{i}$ & $\begin{array}{l}0 \\
\stackrel{-}{0} \\
\text { - }\end{array}$ & $\circ$ & $\begin{array}{l}0 \\
\stackrel{0}{R}\end{array}$ & $\begin{array}{l}0 \\
\omega^{-}\end{array}$ & $\begin{array}{l}\infty \\
\infty^{-}\end{array}$ & 离 & $\begin{array}{l}0 \\
\stackrel{-}{0}\end{array}$ \\
\hline & $\begin{array}{l}z \\
\Sigma\end{array}$ & 4 & $m$ & L & $\nabla$ & $\rightarrow$ & $\stackrel{M}{\rightarrow}$ & 4 & $\stackrel{\sim}{\sim}$ & $\sim$ & $m$ & م & ले \\
\hline & $\underset{I}{\mathbb{T}}$ & 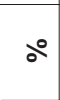 & ' & $\stackrel{m}{m} \stackrel{m}{m}^{m}$ & $\begin{array}{l}\hat{\theta} \\
\ddot{\theta}\end{array}$ & ' & $\begin{array}{l}0 \\
\stackrel{0}{0} \\
\stackrel{-1}{0}\end{array}$ & $\therefore$ & $\begin{array}{l} \\
\theta_{0}^{-}\end{array}$ & : & $\begin{array}{l}m \\
\infty\end{array}$ & ' & $\begin{array}{l}0 \\
\stackrel{-}{0}\end{array}$ \\
\hline$\overline{\bar{o}}$ & $\begin{array}{l}z \\
u\end{array}$ & 4 & ' & $\rightarrow$ & $N$ & ' & $m$ & 4 & $\infty$ & $m$ & $\rightarrow$ & ' & $\underset{\Im}{\sim}$ \\
\hline$\frac{\vec{R}}{0}$ & $\underset{I I}{\underset{7}{7}}$ & $\circ$ & ' & $\begin{array}{l}0 \\
\stackrel{0}{0} \\
\text { - }\end{array}$ & ' & & $\begin{array}{l}0 \\
\text { ¿ } \\
\text { - }\end{array}$ & $\circ$ & $\begin{array}{l}\text { m. } \\
\tilde{\sigma}\end{array}$ & ' & ' & $\hat{i}$ & $\begin{array}{l}0 \\
\stackrel{-}{0}\end{array}$ \\
\hline & $\frac{z}{\Sigma}$ & - & ' & $\dashv$ & ' & ' & $\rightarrow$ & + & $\underset{\neg}{\Im}$ & ' & ' & $\dashv$ & $\underset{\rightarrow}{\stackrel{M}{*}}$ \\
\hline & $\begin{array}{l}\widehat{m} \\
11\end{array}$ & $\circ$ & $\begin{array}{l}\stackrel{0}{\infty} \\
\stackrel{\infty}{\sim}\end{array}$ & $\begin{array}{l}0 \\
\stackrel{\infty}{N}\end{array}$ & $\begin{array}{l}\infty \\
\stackrel{\sim}{y}\end{array}$ & ' & $\begin{array}{l}0 \\
\stackrel{0}{0} \\
0\end{array}$ & $\circ$ & $\begin{array}{l}\circ \\
\stackrel{\circ}{\wedge}\end{array}$ & ' & ' & 吕 & $\begin{array}{l}0 \\
\stackrel{0}{-1} \\
\text { - }\end{array}$ \\
\hline $\bar{o}$ & $\underset{u}{z}$ & 4 & $\sim$ & $\sim$ & m & ' & $\sim$ & 4 & $a$ & ' & ' & $m$ & $\approx$ \\
\hline $\begin{array}{l}\vec{r} \\
\frac{\pi}{0}\end{array}$ & $\begin{array}{l}\widetilde{Q} \\
\text { II } \\
z \\
\Sigma\end{array}$ & $\begin{array}{l}\circ \\
-\end{array}$ & $\begin{array}{l}\stackrel{\circ}{N} \\
\text { m }\end{array}$ & $\begin{array}{l}\stackrel{m}{\infty} \\
\stackrel{m}{-} \\
+\end{array}$ & $\begin{array}{l}\stackrel{m}{m} \\
\nabla\end{array}$ & $\begin{array}{l}m^{m} \\
\infty^{-} \\
\rightarrow\end{array}$ & \begin{tabular}{l}
0 \\
0 \\
8 \\
-1 \\
\multirow{-}{*}{}
\end{tabular} & + & 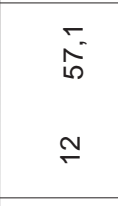 & $\begin{array}{l}\text { ம0 } \\
\text { o. }\end{array}$ & $\begin{array}{l}m \\
\stackrel{m}{-} \\
m\end{array}$ & $\begin{array}{l}\vec{\sigma} \\
\vec{\sigma} \\
+\end{array}$ & $\begin{array}{l}0 \\
\stackrel{-}{\circ} \\
\vec{N}\end{array}$ \\
\hline 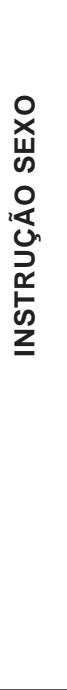 & 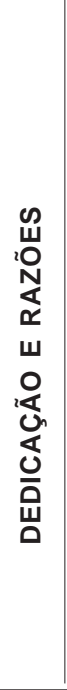 & 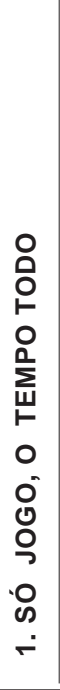 & 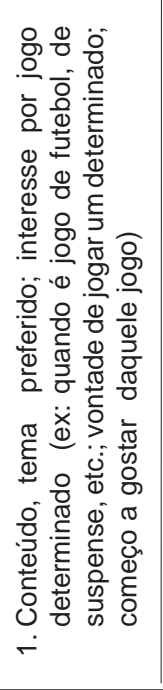 & 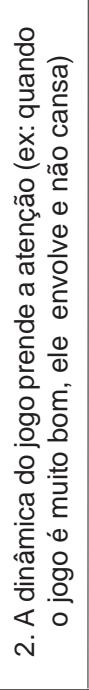 & 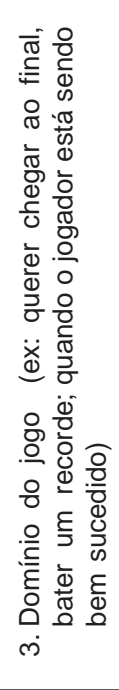 & 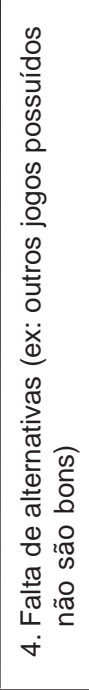 & 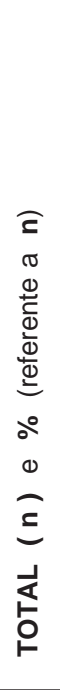 & $\begin{array}{l}n \\
0 \\
0 \\
0 \\
0 \\
0 \\
\frac{N}{5} \\
\Sigma \\
\partial \\
0 \\
m \\
\text { N }\end{array}$ & 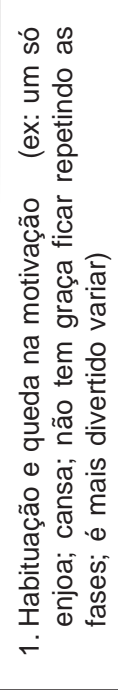 & 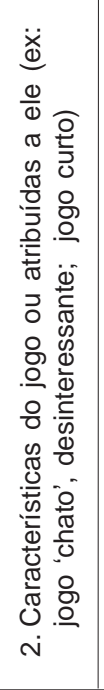 & 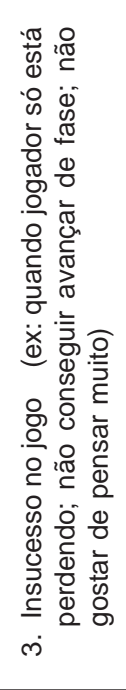 & 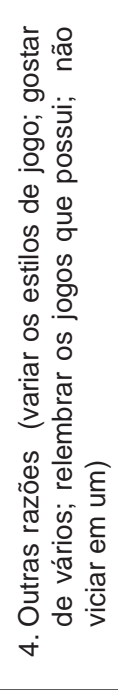 & 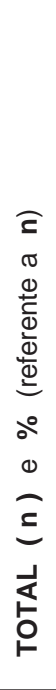 \\
\hline
\end{tabular}


Sobre o uso do tempo em cada situação de jogo - às vezes, concentrado em um só jogo; às vezes, em dois; às vezes, em três ou mais jogos - vários sujeitos assinalaram mais de uma alternativa (Tabela 3). Para o brincar com um só jogo em um dado período, os dados suficientes para aplicação da prova de $\mathrm{c}^{2}$. No conjunto dos meninos, a concentração temporária em um jogo ligou-se a três determinantes: dinâmica do jogo que mantinha a atenção e o interesse $(38,4 \%)$; busca de domínio do jogo, sendo motivadores seus desafios e sucesso atingido $(30,8)$; atração pelo conteúdo de um jogo $(23,1 \%)$. Entre as 25 meninas, predominou a busca de domínio do jogo $(50,0 \%)$. Do total de meninos e de meninas, a maioria (71,0\%) vinculou a prática de dois ou mais jogos em um período, à queda de interesse pela repetição constante de um jogo ou de fases semelhantes, fator que diferiu significativamente do conjunto das outras razões (meninos: $\chi^{2}=5,76 ; \chi^{2} \mathrm{c}=5,41$; g.I. $=1 ; p<0,02 ;$ meninas: $\chi^{2}=4,16 ; \chi^{2} c=3,84$; g.l. $=1 ; p<0,05)$ e corroborou os achados de Campos, Yukumitsu, Fontealba e Bomtempo (1994) em jogadores de videogames, sobre a necessidade de variação.

Na identificação de 4 jogos que sabiam jogar, houve grande dispersão: 57 citados pelos 40 meninos e 36 , pelas 25 meninas. Foram, então, reunidos em 10 categorias a partir das nomeações dos sujeitos e de sites de jogos (ex: www.gamesdomain.com/spoile; w w w . m i c r o s of t . com/ga m e s; www.terra.com.br/games/; www.uol.com.br/ outerspace): basquete; corrida; futebol; outros esportes; ação com luta/matar ou morrer; ação e estratégia em aventura ou RPG (role playing game); baralho; quebra-cabeça e estratégia; simulação; outros jogos. No enquadramento dos jogos de baralho e esportes não houve dificuldades, mas a separação em jogos de ação, aventura ou estratégia envolveu critérios não exaustivos, com duas decorrências, presentes em sites, nas caracterizações dos sujeitos, e na literatura (Retschtzki \& Gurtner,1995): jogos bem diversos em uma mesma categoria e um mesmo jogo cabível em mais de uma classe.

Retschtzki \& Gurtner (1995) trabalham com quatro classes gerais: ação, aventura, simulação e reflexão. Nas de ação, incluem jogos de tiro (combates para destruir um inimigo: um personagem, uma nave, etc.); jogos de plataforma (o herói galga plataformas por meio de escadas, saltos, cordas, etc.); jogos de habilidade (precisão de movimentos, como no tênis, bilhar, golfe). Em relação aos sites e caracterizações dos sujeitos, há convergência quanto a tratar os jogos de luta e combate como de ação, mas divergência nos de esportes que não são destacados por Retschtzki \& Gurtner (1995). Estes autores reúnem jogos de aventura e RPG e os sites, os de aventura, estratégia e RPG. Em geral, os de aventura/RPG têm enredo fantástico e cenário épico (conquista de um mundo imaginário, busca de um tesouro, etc.). $\mathrm{O}$ jogador atua como o herói que busca soluções, daí a conexão deste grupo com o fator estratégia. Os de simulação comportam situações ou papéis do cotidiano (ex: simuladores de vôo, em que o jogador pilota um avião enfrentando as exigências desta atividade). Neste grupo, Retschtzki \& Gurtner (1995) incluem futebol, basquete, etc., como simulações esportivas. Nos jogos de reflexão situam os de estratégia (xadrez, damas, go, gamão) e jogos de salão (memória, jogos de baralho, banco imobiliário, etc.).

Pela divergência entre a caracterização destes autores e a dos sujeitos, nas 10 categorias empregadas foi priorizada a dos sujeitos para preservar suas representações sobre jogos. Mas subsistiram problemas. Muitos jogos de corrida ou aventura envolvem embates agressivos e caberia classificá-los como de ação/luta/matar-morrer. O fator estratégia também confunde: todo jogo tem um objetivo e implica estratégias, a diferença advindo do contexto que as exige - esporte, simulação, jogo com enredo ou de estrita solução de problemas abstratos. Assim, as 10 
categorias usadas constituem uma aproximação inicial, mas, como os dados ainda continuaram dispersos, elas foram aglutinadas em três tipos gerais de jogos, como mostra a Tabela 4: esportes; ação (luta/matar-morrer + aventura/ RPG/ estratégia); outros (baralho + quebra-cabeça/ estratégia + simulação + outros jogos).

Os dois sexos diferiram no seu conhecimento dos tipos de jogos $\left(\chi^{2}=44,38\right.$; $\left.\chi^{2} \mathrm{c}=13,82 ; \mathrm{gl}=2 ; \mathrm{p}<0,001\right)$. Entre os 40 meninos, os tipos e categorias mais citados foram: esportes (51,9\%), em especial, de corrida (34,4\%); jogos de ação (33,1\%), a maior parte de matar-morrer (27,5\%). Entre as 25 meninas, outros tipos (44\%), com predomínio de quebra-cabeça/estratégia (22,0\%) e baralho (20,0\%); jogos de ação (26,0\%), de matar-morrer como de aventura/ estratégia. O jogo mais conhecido entre meninos foi Doom (matar-morrer; 27,5\%) e das meninas, Paciência (baralho; 68,0\%). Se Campos, Yukumitsu, Fontealba e Bomtempo (1994) não ofereceram dados do sexo feminino, por sua ausência entre usuários de locadoras de videogames, os aqui obtidos, embora de uma amostra limitada, reforçaram os dados internacionais sobre diferenças de gênero: meninos não só jogavam mais do que meninas, mas mostravam um conhecimento mais amplo.

O jogo preferido também se mostrou bastante personalizado. No conjunto dos 40 meninos emergiram 25 jogos diferentes e só tiveram algum destaque Need for Speed (corrida), Fifa Soccer (futebol) e Duke Nuken 3D (matar-morrer), cada um com 4 ou 5 indicações. Entre as 25 meninas foram citados 18 jogos, nenhum preferido por não mais do que duas delas. Desta forma, as preferências foram aglutinadas nas categorias e nos tipos mais gerais de jogos (Tabela 5).
Para os 40 meninos, a preferência recaiu em esportes $(55,0 \%)$ e ação $(35,0 \%)$ $\left(\chi^{2}=12,23 ; \chi^{2} c=9,21 ;\right.$ g.l. $=2 ; p<0,01$, para esportes vs. ação vs outros tipos + sem resposta). O mesmo se deu com os meninos mais novos (esportes: 46,2\%, principalmente corrida; ação: 42,3\%), mas, com os mais velhos, centrou-se em esportes $(71,4 \%)$, em especial, corrida $\left(\chi^{2}=2,83 ; \chi^{2} c=2,71 ;\right.$ g.l. $=1$; $\mathrm{p}<0,05)$. Esta diferenciação etária discrepou de dados sobre atração por jogos de ação/ violência entre adolescentes e crianças (Buchman \& Funk ,1996; Campos, Yukumitsu, Fontealba e Bomtempo, 1994). Dada a agressão em jogos de matar-morrer, como em certos jogos de esporte (em especial, corrida) e de aventura-estratégia, a diferença pode ter sido aparente, mascarada pela caracterização dos sujeitos. Assim, a questão pede mais estudos com amostras maiores, foco em jogos específicos e análise do seu conteúdo, para clarificar o real determinante das preferências: o esporte, a ação/aventura, a agressão, ou a interação desta com cada um dos outros fatores.

No conjunto das meninas, o jogo preferido recaiu, equitativamente, nos três tipos gerais (esportes vs. ação vs. outros jogos: $\chi^{2}=2,43$; $\left.\chi^{2} \mathrm{c}=5,99 ; \mathrm{g} . \mathrm{I} .=2 ; \mathrm{p}<0,05\right)$, para os quais as frequências também foram semelhantes nos dois grupos etários. Os dados não apoiaram aqueles de Buchman \& Funk (1996) sobre preferência por jogos violentos, também por meninas e ao longo das séries. Ainda, sugeriram indefinição de interesses das meninas enquanto grupo, o que pode refletir a inexistência ou insuficiência de jogos com temas femininos e poderia explicar, também, o fato de que as meninas estudadas dedicavam menos tempo aos jogos de computador do que os meninos. 


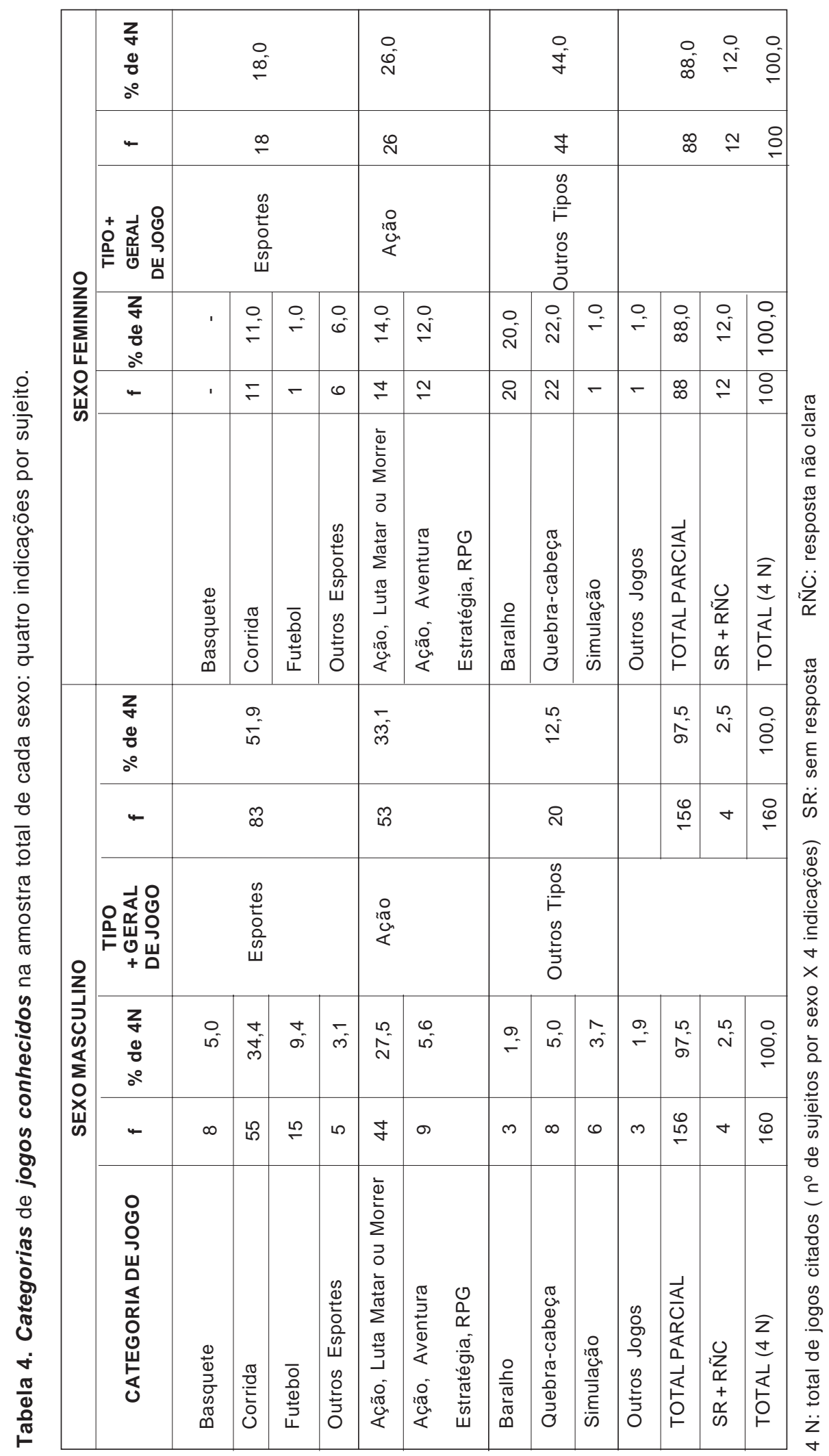


Tabela 5. Distribuição dos jogos preferidos segundo seu tipo mais geral: uma indicação por sujeito

\begin{tabular}{|c|c|c|c|c|c|c|c|c|c|c|c|c|}
\hline \multirow{3}{*}{$\begin{array}{l}\text { INSTRUÇÃO } \\
\text { SEXO } \\
\text { O + GERAL de JOGO }\end{array}$} & \multicolumn{4}{|c|}{ GRUPOI } & \multicolumn{4}{|c|}{ GRUPO II } & \multicolumn{4}{|c|}{ AMOSTRA TOTAL } \\
\hline & \multicolumn{2}{|c|}{$M(N=26)$} & \multicolumn{2}{|c|}{$F(N=13)$} & \multicolumn{2}{|c|}{$M(N=14)$} & \multicolumn{2}{|c|}{$F(N=12)$} & \multicolumn{2}{|c|}{$M(N=40)$} & \multicolumn{2}{|c|}{$F(N=25)$} \\
\hline & $f$ & $\%$ & $f$ & $\%$ & $f$ & $\%$ & $f$ & $\%$ & $f$ & $\%$ & $f$ & $\%$ \\
\hline ESPORTES & 12 & 46,2 & 3 & 23,1 & 10 & 71,4 & 2 & 16,7 & 22 & 55,0 & 5 & 20,0 \\
\hline AÇÃO & 11 & 42,3 & 5 & 38,4 & 3 & 21,4 & 6 & 50,0 & 14 & 35,0 & 11 & 44,0 \\
\hline OUTROSTIPOS & 2 & 7,7 & 3 & 23,1 & 1 & 7,7 & 4 & 33,4 & 3 & 7,5 & 7 & 28,0 \\
\hline TOTAL PARCIAL & 25 & 96,2 & 11 & 84,6 & 14 & 100,0 & 12 & 100,0 & 39 & 97,5 & 23 & 92,0 \\
\hline R Ñ C & 1 & 3,8 & 2 & 15,4 & - & - & - & - & 1 & 2,5 & 2 & 8,0 \\
\hline TOTAL GERAL & 26 & 100,0 & 13 & 100,0 & 14 & 100,0 & 12 & 100,0 & 40 & 100,0 & 25 & 100,0 \\
\hline
\end{tabular}

R Ñ C: resposta não clara

Para identificar os requisitos do jogo preferido, foram propostas as alternativas: a) necessidade de estratégias; b) de atenção, rapidez e movimentos precisos; c) de (a) e (b); d) impossibilidade de criar estratégias para vencer o computador; é preciso memorizar a seqüência de acontecimentos que é sempre a mesma e, a cada vez que se joga, sabendo o que vai acontecer, é preciso atenção, movimentos rápidos e certos. Mesmo na distribuição apenas por sexo e tipos gerais de jogos, os dados ficaram muito dispersos e a questão, inconclusa. Ao se reportarem ao conjunto dos jogos, os dados não informaram as concepções dos sujeitos sobre jogos específicos. Assim sendo, estudar a compreensão de jogadores sobre um jogo e as suas exigências implica estudar sujeitos atraídos pelo mesmo jogo. Além disso, exige amostras maiores que permitam o exame mais acurado da influência das variáveis sexo e instrução.

Sobre razões da preferência por um jogo, a maioria indicou vários aspectos, muitos citados uma só vez. A Tabela 6 só incluiu razões citadas por, no mínimo, 10,0\% dos sujeitos, os quais foram separados só por sexo. Ainda assim, para os dados femininos só foi possível a distribuição das razões para o conjunto dos jogos. Então, não relacionadas a jogos específicos, as principais razões da preferência feminina foram: desafios do jogo e suas exigências de estratégia $(60,0 \%)$; diversão e interesse despertados (44,0\%); muita ação e exigência de movimentos ágeis (32,0\%).

Para o total de meninos e o conjunto de jogos (esportes + ação + outros tipos), as razões da preferência foram desafios e exigências de estratégia (62,5\%) e conteúdo do jogo (45,0\%). Entre meninos cujo jogo preferido era de esporte, as razões mais expressivas foram o conteúdo (50\%) e desafios/estratégias (45,5\%), com a ação destacada por apenas 18,2\%. A preferência por um jogo de ação vinculou-se mais aos desafioslestratégias (85,7\%), mas conteúdo (50,0\%) e ação $(42,9 \%)$ também foram razões fortes. Entre os meninos, independente do tipo de jogo, o status ocupado por seu conteúdo ( $2^{\circ}$ fator da preferência) destoou dos achados de Campos, Yukumitsu, Fontealba e Bomtempo (1994), para cujos sujeitos o conteúdo foi o motivador menos freqüente. Também, não apoiou as análises de Greenfield (1984/1988) sobre importância maior da ação na atração exercida por um jogo. Pelos dados obtidos, o conteúdo sobrepujou a ação ou teve importância semelhante, como fator motivacional. Para os diferentes jogos, 
Tabela 6. Distribuição das razões da preferência por determinado tipo de jogo computadorizado

\begin{tabular}{|c|c|c|c|c|c|c|c|c|}
\hline SEXO & & & MAS & ULINO & & & FE & NINO \\
\hline TIPOS + GERAIS DE JOGOS & ESF & RTES & & & $\begin{array}{l}\text { CO } \\
\text { DOS }\end{array}$ & $\begin{array}{l}\text { UNTO } \\
\text { OGOS }\end{array}$ & $\begin{array}{l}\text { COI } \\
\text { DOS }\end{array}$ & $\begin{array}{l}\text { UNTO } \\
\text { OGOS }\end{array}$ \\
\hline & & 22 & & 14 & & 40 & & 25 \\
\hline RAZÕES DA PREFERÊNCIA POR DETERMINADO JOGO & $f$ & $\%(n)$ & $f$ & $\%(n)$ & $f$ & $\%(n)$ & $f$ & $\%(n)$ \\
\hline Jogo com muita ação, movimentos ágeis e velozes & 4 & 18,2 & 6 & 42,9 & 11 & 27,5 & 8 & 32,0 \\
\hline $\begin{array}{l}\text { Conteúdo do jogo (ex de respostas: esporte; mistério; } \\
\text { luta, agressão, mortes) }\end{array}$ & 11 & 50,0 & 7 & 50,0 & 18 & 45,0 & 3 & 12,0 \\
\hline $\begin{array}{l}\text { Exigências de estratégia, raciocínio e pensamento, } \\
\text { imaginação e antecipação; desafios e dificuldades; } \\
\text { querer vencer o computador }\end{array}$ & 10 & 45,5 & 12 & 85,7 & 25 & 62,5 & 15 & 60,0 \\
\hline Exigências de atenção e concentração & - & - & 4 & 28,6 & 6 & 15,0 & 4 & 16,0 \\
\hline Bom aspecto gráfico; cenários bem desenvolvidos & 4 & 18,2 & - & - & 6 & 15,0 & - & - \\
\hline Jogo interessante, divertido, engraçado ou envolvente & 3 & 13,6 & 5 & 35,7 & 8 & 20,0 & 11 & 44,0 \\
\hline
\end{tabular}

$\mathrm{n}$ : total de sujeitos com jogo preferido de cada tipo

desafios e estratégias se revelaram mais importantes. Os dados não desqualificam o papel da ação e dos movimentos, mas sinalizam priorizações dos sujeitos no campo da solução de problemas, o que soa como um deslocamento benéfico, mesmo sem caber sua generalização. Exatamente neste sentido, são indispensáveis novas pesquisas.

Para os dois sexos, desafios e estratégias constituíram a razão principal da preferência por um jogo. O que os diferenciou mais foi a importância também dada pelos meninos ao conteúdo - um aspecto objetivo do jogo - enquanto o segundo fator da preferência feminina foi a diversão e interesse despertados, dimensões subjetivas que só podem ser apreciadas se experienciado um jogo. Pode-se hipotetizar que meninos disponham de mais de um critério prévio para aproximação e seleção de jogos - a motivação para atividades que, em parte, ocorrem no real e aparecem em jogos de esportes, lutas, aventuras - enquanto esta condição pode não proceder para as meninas. Entre aquelas estudadas, o lugar secundário atribuído ao conteúdo do jogo $(12,0 \%)$ pode explicar o fato de que jogavam menos, de não terem exibido preferências claras como grupo e pode, principalmente, refletir a falta de jogos centrados em temas e interesses femininos.

\section{CONSIDERAÇÕES FINAIS}

Com caráter exploratório, o estudo centrou-se em uma amostra bem específica - classe média, escola particular, instrução entre $6^{\mathrm{a}} \mathrm{e}$ $8^{a}$ séries. Mesmo não generalizáveis, os informes obtidos sinalizaram aspectos relevantes, no sentido de uma primeira aproximação aos hábitos de adolescentes brasileiros na sua prática de jogos computadorizados. 
A maioria dos meninos gostava muito de jogos computadorizados e investia muito mais tempo semanal do que as meninas. Mas, exceto casos isolados, sua dedicação não se mostrou excessiva e, para a maioria, estava sob algum controle, autônomo ou parental. A preferência dos mais novos ( $6^{\mathrm{a}}$ - $7^{\mathrm{a}}$ séries) por esportes e jogos de ação (matar-morrer + aventura-estratégia), mas por esportes entre os mais velhos ( $8^{a}$ série), divergiu de outros estudos que apontam atração por jogos violentos nas várias idades (Buchman \& Funk, 1996; Campos, Yukumitsu, Fontealba e Bomtempo, 1994). Preferências masculinas derivadas dos desafios e exigências de estratégias e, depois, do conteúdo do jogo, também divergiram das evidências sobre a ação como principal fator motivacional (Campos, Yukumitsu, Fontealba e Bomtempo, 1994; Greenfield, 1984/1988).

Em termos semanais, as meninas jogavam pouco e sua dedicação era regulada por sua motivação (alta ou baixa) ou por controle autônomo. Suas preferências vincularam-se aos desafios e exigências de estratégias e, também, ao interesse e à diversão gerados por um jogo, embora, enquanto grupo, não se tenham revelado preferências claras por tipos específicos de jogo.

A literatura brasileira dos anos 90 comtém inúmeros artigos reflexivos sobre benefícios, ou não, do computador na escola e estudos empíricos centrados na linguagem $L O G O$, mas carece daqueles sobre padrões de jogo em crianças e adolescentes brasileiros e sobre jogos computadorizados. Em termos da educação e pesquisa nacionais, a inserção do computador junto à classe média e a prática de jogos por adolescentes e crianças pedem consideração, dentre outros, de dois aspectos. De um lado, a potencialidade educacional de jogos de computador, apontada internacionalmente e, entre nós, por Lüders (1998). De outro lado, aqueles que praticam tais jogos estão se apropriando de um capital cultural que afeta formas de pensar, abordar e solucionar problemas (Greenfield, 1984/1988). Que favorece habilidades de indução (Lüders, 1998), atenção e coordenação de variáveis dinâmicas em interação simultânea - imagens animadas (Retschitzki \& Gurtner, 1995), como de antecipação, planejamento e elaboração de estratégias (Horak, 1990).

Este estudo não tratou das relações entre jogos de computador, aprendizagem e educação, não por desconsiderá-las, mas porque teve outro núcleo, por entender necessário o conhecimento sobre os hábitos de jogo de estudantes brasileiros e oportunidades de praticá-los. Enquanto um capital cultural, o acesso a jogos de computador e sua prática configuram um novo fator de desigualdades entre sujeitos sob condições socioeconômicas diversas. Mas, como apontou este estudo, também se colocam desigualdades entre sexos na dedicação a tais jogos, nas preferências e nos motivadores para esta atividade, sinalizando oportunidades diferenciadas de acesso.

Entre os dados obtidos, uma situação pode ter valor ilustrativo, ainda que não significativa em termos quantitativos: nenhuma menina apontou Tomb Raider como jogo preferido, o que se deu com dois meninos; Prince of Persia foi citado como preferido por uma menina, mas não por meninos. Tomb Raider constitui uma série de jogos cujo personagem central é uma arqueóloga heroína, não herói. Segundo os referenciados sites de jogos, trata-se de personagem bonita e com apelos eróticos, hábil em armas e lutas, que resolve enigmas e vence inimigos. Prince of Persia reproduz aventuras tipo Mil e uma Noites e seu herói - um príncipe - luta e soluciona situações, defendendo a 'mocinha'. Os dois jogos são de aventura, mas o último tem um contexto romântico consistente com o estereótipo feminino. A heroína de Tomb Raider aglutina atributos dos estereótipos masculino e feminino, mas a atratividade da série sobre meninos pode resultar da combinação entre 
apelo sexual e um possível senso de domínio do jogador sobre a personagem - é ele que a conduz - o que pode implicar, não sua identificação com a heroína, mas a preservação do seu senso de masculinidade: o jogador pode sentir-se como o efetivo herói de cujas ações a personagem depende para ser bem sucedida. Tais condições poderiam explicar a presença, no grupo estudado, de meninos atraídos por este jogo, mas não de meninas. Uma hipótese, então, é que centrar um jogo em um personagem feminino não significa uma automática consideração a interesses femininos, se a trama reproduzir situações mais dirigidas a estereótipos masculinos.

Nesta ótica, a sugestão já feita de pesquisas sobre o conteúdo de jogos deve contemplar não só o fator agressão, mas os estereótipos de gênero. A produção cultural ligada à informática, pelo menos aos jogos, pode estar fortalecendo tais estereótipos e afastando meninas deste campo de atividades, na medida em que temas, preferências e padrões de conduta masculinos sejam mais contemplados. Consideradas as possíveis influências cognitivas dos jogos de computador, configura-se um quadro de prejuízos de oportunidades para o sexo feminino.

A falta de jogos de computador e de outros softwares sensíveis às diferenças de gênero tem sido identificada como uma causa de desinteresse de meninas por tecnologias informatizadas (Koch, 1994; Miller, et al., 1996; Valenza, 1997). Com outras atitudes e motivações, em jogos, meninas valorizam mais a cooperação do que a competição, interessamse por simulações e por interação com personagens masculinos (Koch, 1994; Miller, et. al., 1997). Para encorajar o envolvimento feminino, várias propostas reportam-se ao contexto escolar: classes só femininas para disciplinas como matemática e computação; introdução precoce às tecnologias informatizadas, sua integração em diferentes áreas e pareamento de alunos para favorecer intercâmbios cooperativos; softwares que estimulem a criatividade e a cooperação; exposição a modelos femininos com domínio em informática (Koch, 1994; Miller, et al., 1997; Valenza, 1997). Outros estudos envolvem projetos "construcionistas" (Kafai, 1996a): criação de jogos de computador recreativos e educacionais por crianças e adolescentes que, sem precisar aprender linguagens de programação, podem elaborar mundos imaginários, estórias e personagens com diferentes atributos. Estes projetos constituem contextos de aprendizagem e recursos para identificar valores, atitudes e interesses sexualmente tipificados, por meio das construções dos sujeitos (Kafai, 1996b).

Nesta linha, legitimam-se pesquisas brasileiras que, direcionadas ao sexo feminino, possam - se não contribuir para alterações na política de produção de jogos de computador, já que se trata de produção internacional - pelo menos, identificar jogos mais sensíveis a interesses femininos, minimizando a desigualdade nas oportunidades de usufruto desta produção cultural.

Outro ponto a considerar advém da referência, por um terço dos meninos estudados, a restrições parentais ao tempo com jogos (controle heterônomo). Em termos desenvolvimentistas e educacionais, seria mais produtivo este controle indo além da restrição, para assumir uma feição formativa. Nesta linha, Funk \& Buchman (apud Cesarone, 1998) oferecem várias recomendações aos pais: conhecer o conteúdo de jogos através de seus manuais, observando seus filhos jogarem e, eles próprios, jogando; estabelecer limites ao uso e tempo com jogos; discutir os jogos com os filhos e a diferença entre a violência ficcional nas mídias e na vida real; conhecer a classificação de jogos segundo seu conteúdo de violência, sexo, nudez e linguagem (sistema do Recreational Software Advisory Council) e sua adequação etária (sistema do Entertainment Software Rating Board). Como tais orientações se centram nas questões da 
violência, linguagem, e sexo, também é cabível o alerta aos pais para os estereótipos de gênero, na perspectiva de uma educação familiar voltada a um maior igualitarismo intersexos e à formação, entre os filhos, de atitudes reflexivas e críticas sobre este instrumento de lazer - os jogos computadorizados.

Como último ponto, cabe considerar as preferências tão personalizadas por jogos de computador: um jogo diferente para cada 1,4 meninas e cada 1,6 meninos. Com isto, não se atingiu um dos objetivos do estudo que era encontrar bases para a seleção de um jogo (um dos preferidos) tendo em vista uma pesquisa microgenética, que, já realizada, se baseou em outros critérios.

Para além deste aspecto, qual o significado de nenhum jogo ter-se revelado catalisador do interesse dos adolescentes estudados? Teria sido uma especificidade da amostra examinada? Ou uma condição inerente à época em que foi realizado o estudo? Em termos medianos, os sujeitos mais velhos e os mais novos possuíam computador há menos de 3 e de 2 anos, respectivamente. Tal condição, mais a novidade destes jogos e a expansão contínua na sua oferta, a familiariza ção e domínio de diferentes jogos - tudo isto poderia favorecer vínculos frágeis, cada jogo sendo logo trocado por outro mais atual, repercutindo em ausência de interesses grupais.

Ou, interesses efêmeros seriam a marca da relação entre adolescentes e tais objetos virtuais? Dados atuais da mídia popular falam mais a favor da interpretação acima do que de interesses tão descartáveis. Hoje se expandem as chamadas LAN houses, casas que oferecem jogos em rede: vários computadores interconectados e disponibilizando o mesmo jogo, de modo que vários sujeitos jogam, competindo entre si. Tais casas atuam, comumente, com um número delimitado de jogos. O centro da atividade é o jogo entre parceiros reais e a formação de times que buscam tornar-se expertos em um dado jogo, inclusive com formação de ligas e campeonatos nacionais e internacionais. Acresça-se que as LAN houses são pontos de encontro desses times e de torcidas (Informática, 2001, 24/9).

O domínio especializado de certos jogos supõe interesses mais estáveis e convergentes entre grupos de adolescentes. A dinâmica de jogos propiciada por tais casas resgata 0 contexto de interações diretas, no qual o computador deixa de ser oponente para recolocar-se como mediador de interações humanas. Tudo isto delineia novas frentes de estudo sobre hábitos e padrões de jogos computadorizados entre crianças e adolescentes, destacando-se a relevância do prosseguimento de investigações nesta área.

\section{REFERÊNCIAS}

AZAMBUJA, R. S. (1995). A decodificação do discurso adulto da televisão pelo público infantil. Em M. W. de Sousa (Org.) Sujeito, o lado oculto do receptor. São Paulo, SP: Brasiliense, 123 - 133.

BARNETT, M. A., Vitaglione, G. D., Harper, K. K., Quackenbush, S. W., Steadman, L. A., Valdez, B. S. (1997). Late adolescents' experiences and attitudes toward videogames. Journal of Applied Social Psychology, 27(15):1316-1334. Abstract from DIALOG File: PsycINFO/PsycLIT 1996-3/98, Item 1997-43040-002.

BIEGEN, E. R. E. (1985). The effects of video game usage, family press for achievement, and school-related activities on school outcomes. Dissertation Abstracts International , 46/07A: 1872. Abstract from DIALOG File: Dissertation Abstracts Online, Item AAD85-15609.

BROWN, R. M., Hall, L. R., Holtzer, R., Brown, S. L., Brown, N. L. (1997). Gender and video game performance. Sex-Roles, 36 (11-12): 793-812. Abstract from DIALOG File: PsycINFO/PsycLIT 1996-3/98, Item 1997-07042-007. 
BUCHMAN, D. D., Funk, J. B. (1996). Video and computer games in the '90s: Children's time commitment and game preference. Children Today, 24 ( 1 ): 12-15. Abstract from DIALOG File: ERIC, Item EJ 544891.

CAMPOS, L. F. L., Yukumitsu, M. T. C., Fontealba, L. H., Bomtempo, E.(1994). Videogame: Um estudo sobre as preferências de um grupo de crianças e adolescentes. Estudos de Psicologia, Campinas, 11(3): 65-72.

CESARONE, B. (1994). Video Games and Children. Retrieved from ERIC online database, Item ED365477 94., on the URL: ht t p: //www.ed.gov/databases/ ERIC_Digests/index.html

CESARONE, B. (1998). Video Games: Research, Ratings, Recommendations. Retrieved from ERIC online database, Item ED424038 98, on the URL: http:// www.ed.gov/databases/ ERIC_Digests/ index.html

CHAPPELL, K. K. (1997). Investigating the impact of elements in educational mathematics software on girls' attitudes. Journal of Educational Computing Research, 17 (2): 119-133. Retrieved from ERIC online database, item EJ570589, on the URL: http://www.ed.gov/databases/ ERIC_Digest/index.html

DEMPSEY, J. V. et al. (1994). Instructional gaming: implications for instructional technology. Annual Meeting of the Association for Educational Communications, Nashville, TN (Paper presented). Retrieved from ERIC online database, Item ED368345 on the URL: http:/ /www.ed.gov/databases/ERIC_Digests/ index.html

DOWNES, T., Reddacliff, C., Moont, S. (1995). Children's use of electronic technologies in the home (Research report). ERIC online database, Item ED416841, URL: http:// www.ed.gov/databases/ ERIC_ Digests / index.html
EMES, C. E. (1997). Is Mr. Pac Man eating our children? A review of the effect of video games on children. Canadian Journal of Psychiatry, 42 (4): 409-414. Abstract from PsycINFO/PsycLIT 1996-3/98, Item 199706333-007.

FUNK, J. B., Buchman, D. D. (1996a). Children's perceptions of gender differences in social approval for playing electronic games. Sex Roles, 35 ( 3/4 ) 219-231. Abstract from DIALOG File: ERIC, Item EJ 537064.

FUNK, J. B., Buchman, D. D. (1996b). Playing violent video and computer games and adolescent self-concept. Journal of Communication, 46 ( 2 ) 19-32. Abstract from DIALOG File: ERIC, Item EJ 542545.

GLISSOV, P.et al. (1994). Chips with everything: Personal attributes of heavy computer users. Educational Studies, 20 (3): 367-77. Retrieved from ERIC online database, Item EJ507526, URL: http:// www.ed.gov/ databases/ ERIC_Digests/ index.html

GODOY, N. (1996,17/7). Pais, filhos \& computadores. ISTO É, São Paulo, 1398: 100-107.

GREENFIELD, P.M. (1988). O desenvolvimento do raciocínio na era da eletrônica: Os efeitos da TV, computadores e videogames. Trad. C. Bonamine. São Paulo: Summus (Orig.: 1984).

GRIFFITHS, M. (1997). Computer game playing in early adolescence. Youth \& Society, 29 ( 2 ): 223-237. From ERIC online database, Item EJ557763, on the URL: http://www.ed.gov/databases/ ERIC_Digests/index.html

GUPTA, R. (1994). The relationship between video game playing and gambling behavior in children and adolescents. Masters Abstracts, 34 (2): 884. Abstract from DIALOG File 35: Dissert. Abstracts Online, Item AADAA- IMM99903. 
GUPTA, R., Derevensky, J. L. (1996). The relationship between gambling and videogame playing behavior in children and adolescents. Journal of Gambling Studies, 12 (4): 375-394. Abstract from DIALOG File: PsycINFO/ PsycLIT 1996-3/98, Item 1997-04182-001.

HORAK, V. M. (1990). Students' cognitive styles and their use of problem-solving heuristics and metacognitive processes. Annual Meeting of the National Council of Teachers of Math., Salt Lake City, UT, (Paper presented). Retrieved from ERIC online database, Item ED34069, on the URL: http://www.ed.gov/ databases/ ERIC_Digests/index.html

HUSTON, A. C., Wright, J. C., Marquis, J., Green, S. B. (1999). How children spend their time: Television and other activities. Developmental Psychology, 35 (4): 912925. From URL http://www.apa.org./ journals/copyrite.html

Informática (2001, 24/9). Redes de PCs resgatam emoções dos fliperamas. O Estado de São Paulo. São Paulo.

Kafai, Y. B. (1996). Learning design by making games: Children's development of design strategies in the creation of a complex computational artifact. In Kafai, Y. B.; Resnick, M. (Ed) (1996). Constructionism in practice: Designing, thinking, and learning in a digital world.Mahwah, N.J., USA: Lawrence Erlbaum Associates, 71-96. Abstract from PsycLIT 1996-3/98; APA/ PsycINFO.

KAFAI, Y. B. (1996). Electronic play worlds: Gender differences in children's construction of video games. In Kafai, Y. B.; Resnick, M. (Ed) (1996). Constructionism in practice: Designing, thinking, and learning in a digital world. Mahwah, N.J., USA: Lawrence Erlbaum Associates, 97-123. Abstract from PsycLIT 1996-3/98; APA/PsycINFO.

$\mathrm{KOCH}$, M. (1994). No girls allowed! Technos, 3 ( 3 ): 14-19. Retrieved from ERIC online database, item EJ491466, on the URL:
http://www.ed.gov/databases/ERIC_Digest/ index.html

LÜDERS, V. (1998). Jogo informatizado em situação de intervenção: estudo de possíveis efeitos sobre a capacidade de raciocínio indutivo em crianças com dificuldades de aprendizagem. Dissertação de mestrado, UNICAMP, Campinas, SP.

MCCUTCHEON, L. E., Campbell, J. D. (1986). The impact of video game playing on academic performance at a community college. (Research report). Abstract from DIALOG File ERIC, Item EJ331864, JC504099.

MENDES, A. M. T. (1995). Comportamento e recall na audiência de TV. Em M. W. de Sousa (Org.) Sujeito, o lado oculto do receptor. São Paulo, SP: Brasiliense, 99 - 110.

MILLER, L. et. al.(1996).Girls' preferences in software design: Insights from a focus group. Interpersonal Computing and Technolog., 4 (2): 27-36. ERIC online database, item EJ526287, http://www.ed.gov/databases/ ERIC_Digest/index.html

NOGUEIRA, C; Vargas, N. e Nathan, A. (2000). Como os brasileiros usam a internet. Veja. VIDA DIGITAL, 4: 72-77.

PHILLIPS, C. A., Rolls, S., Rouse, A., Griffiths, M. D. (1995). Home video game playing in school-children: A study of incidence and patterns of play. Journal of Adolescence, 18 ( 6 ): 687-691. Abstract from DIALOG File: ERIC, Item EJ 519 525, CG548269.

RETSCHITZKI, J. \& Gurtner, J-L. (1995). L'enfant et l'ordinateur. Aspects psychologiques et pédagogiques des nouvelles technologies de l'information. Mardaga.

SAKAMOTO, A. (1994). Video game use and the development of sociocognitive abilities in children: Three surveys of elementary school students. Journal of Applied Social Psychology, 24 (1): 21-42. PsycINFO, Item 81-37019. 
SANGIORGI, O. (1988). Em W. Garcia, F. J. de Almeida, E. de Mello, O. Sangiorgi (Mesa Redonda). Implicações da informática na educação. Revista Brasileira de Estudos Pedagógicos, 69 (162): 363389.

SATOSHI, S., Yamada, F., Masuda, K., Tada, M. (1993). TV game play and obesity in Japanese school children. Perceptual and Motor Skills, 76: 1121-1122. Abstract from CDAB Online Edition, Item 68-27, http:// www.cdab/index.html

SELNOW, G. W. (1984). Some uses and gratifications of arcade video game playing. [On line]. Annual Meeting of the International Communication Association, San
Francisco, CA (Paper presented). Abstract from DIALOG File: ERIC, Item E248840, IRO11289.

VALENZA, J. K. (1997). Girls + technology = turnoff? Technology Connection, 3 ( 10 ): 20-21. Retrieved from ERIC online database, item EJ541344, on the URL: http:// www.ed.gov/databases/ERIC_Digest/ index.html

VAN SCHIE, E. G., Wiegman, O. (1997). Children and videogames: Leisure, activities, aggression, social integration, and school performance. Journal of Applied Social Psychology, 27 ( 13 ): 1175-1194. Abstract from DIALOG File: PsycINFO/PsycLIT 1996-3/98, Item 1997-05483-004. 